\title{
Why There Cannot be Any Such Thing as "TimeTravel"
}

\author{
Rupert Read, Reader in Philosophy at the University of East Anglia \\ (Norwich)
}

\begin{abstract}
Extending work of Wittgenstein, Lakoff and Johnson I suggest that it is the (spatial) metaphors we rely on in order to conceptualise time that provide an illusory space for time-travel-talk. For example, in the "Moving Time" spatialisation of time, "objects" move past the agent from the future to the past. The objects all move in the same direction - this is mapped to time always moving in the same direction. But then it is easy to imagine suspending this rule, and asking why the objects should not start moving in the opposite direction. This is one way of generating the idea of time-travel "back" into the past. Time-travel-talk essentially involves the unaware projection of fragments of our time-talk - taken from powerful conceptual metaphors - onto the nature of reality itself. Understanding this dissolves away the charm and attractions of such talk.
\end{abstract}

\section{Part I: The Future}

(1) You want to travel forward in time. You want to see the future. You want to bethere.

(2) OK; so you employ a time-machine to zip a hundred years into the future.

(3) But suppose there is another way (perhaps less hazardous, perhaps more feasible)? It may become possible within some of our lifetimes for human beings to be cryogenically preserved for long periods, without suffering any physical deterioration. If you could be frozen for a hundred years and then wake up, then why not call that "time-travel"?

(4) For it seems to bring about exactly what one wanted out of timetravel, out of the "time-machine" concept. One moves (as it seems, from the experiential point of view) forward into the future just like that (A time-machine would be of little use, in which one aged at exactly the same rate as time sped forward...). Is there then any 

good reason not to call a cryogenic preservation unit a "timemachine"?

(5) It seems not. But now, consider: what is cryogenesis, except a long dreamless sleep in which the body-self does not deteriorate? But, given that, then why not call simply going to sleep travelling through time into the future? (Especially (but not only?) if one goes to sleep for a long time... And this of course is hardly an original idea. Think of Sleeping Beauty. Or of Rip van Winkle. My argument in the present paper poses no objection at all to such stories or to "timetravel" tales structurally similar to them.)

(6) It will perhaps be objected that while one is asleep one has dreams. It is not altogether clear that this is an objection at all, given that time-travel for people is usually conceptualised as "continuous," that is, as having a subjective duration, albeit not usually a very long duration.... So it need not differ that much from a night's sleep in which one dreams some. But in any case, there is the phenomenon of the dreamless sleep. (Or at least, there could be: Descartes was surely wrong to deny its very possibility.) So still, why not at least call such sleep "time-travel"?

(7) It will be objected that the body ages during sleep. But there is good biological evidence to doubt that this is straightforwardly or unequivocally true. Much sleep is actually renewing of our organism. (Whereas, if consistently deprived of sleep, one simply dies in a remarkably short time: apparently, somewhere between about 10 days and 10 months. Sleeping less severely risks shortening your life. And: Those of us who have experienced the slow torment of hour after hour insomnia would give a lot, instead, to travel quickly forward to the next morning, via healthy natural sleep.)

(8) Therefore, there seems no good reason to withhold the term "timetravel" from healthy, body-renewing sleep, especially perhaps if it is relatively dreamless. You really can travel to the future. You can see the future.You can be there. Just by going to bed; just by living long enough. (One could perhaps even go one step further. One could of course say that we are all time-travelling all the time, just by virtue of living. Each second that I live, I travel further into the future.)

(9) But this seems an absurd or at least an unsatisfying conclusion. When we initially spoke of "time-travel," we did not want to license the conclusion that simply (say) going to sleep was worth calling "travelling through time." What element is missing? What do we want out of the concept of "time-travel" that going to sleep does not yield us?

(10) What in sleep is missing from time-travel is the essential element of any travel worthy of the name, of tourism and holidaying for instance: 
the ability, at least, to go there and back again. The reason, I believe, why the conclusion that going to sleep is as much travelling through time as is going to the future in a time-machine is repugnant is that we are only prepared to call going to the future "travelling through time" if we can potentially return from the trip.

(11) This implies that time-travel into the future is not enough. (Thus, the "twin paradox" poses no problem at all for my argument. That one twin ages less than another, and can in that sense be regarded as having time-travelled into the future, is not consequentially different from their having undergone cryogenesis. ${ }^{1}$ Time-travel into the future is not really time-travel, not really what we wanted when we desired to travel into the future; unless you can come back again too, not just to meet your twin, but rather (say) to meet your twin when they were younger than when you set out. Or alternatively, of course: to meet yourself before you set out.) In short: Toactually be willing to continue to apply the term "time-travel" to any activity, one requires that one can voyage and return. This implies directly that one will not on reflection countenance speaking of time-travel into the future unless one can already also countenance speaking of time-travel into the past. For, once we arrive in the future (e.g. after a good night's sleep, or through other means), it is pointless to speak of our having travelled through time unless we can return into what has become the past.

(12) Therefore, in order to determine whether or not it makes sense to talk about time-travel, we are compelled to consider whether or not it makes sense to talk about travelling into the past.

\section{Part II: The Past}

(i) You want to travel back in time.You want to see the past.You want to be there.

(ii) OK; so you employ a time-machine to zip a hundred years into the past.

(iii) But a problem immediately arises. You want(-ed) to travel into the past. Into your past. Not into some parallel universe, not into virtual reality. Into the past; you do not want to change anything/ everything such that what you are travelling into is some different

1. For further detail on why "time-dilation" does not amount to time-travel, see note 1 of my "Against 'time-slices'," in this journal, Philosophical Investigations (Read 2003). See also Ch. 19 of Vyvyan Evans's (2003), especially p. 249, for an interesting argument drawing the sting from Special Relativity in this connection. 
history. But how can you venture into the past without changing it? (This point may bring to mind "Niven's Law" of time-travel, that time-travel erases itself, because time-travel back "into the past" could never be into the very past into which one wanted to travel. But my claim here will be more radical: I am suggesting that what this really means is just that there is and can be nothing worth your actually on reflection calling time-travel, at all.)

(iv) For: you already know that there is no record in the past of you having been there, nor of anyone else from the future, no matter how distant or technologically-sophisticated that future becomes.

(v) Maybe you (or they) travelled there very quietly and carefully? Maybe you made no impact?

(vi) But in order not to have changed the past, and made it something other than the very thing that you wanted to voyage into, you cannot have had any impact at all, not even one so slight that it evaded all records and notice. You cannot have affected the energetics of the atmosphere, the trajectories of light-beams, etc. You must have been entirely subtle.

(vii) The implication seems clear: travel back into the past is only possible if the "you" that does the travelling is entirely ethereal. Nonphysical. For the slightest impact upon the past will generate a "causal loop," and thus a familiar paradox of time-travel.

(viii) But now it seems questionable whether it is really you that is doing the "travelling." If the only way that one can travel into the past is by giving up one's bodily existence and becoming spirit, then (unless we make an absolute split between mind or soul and body, unless we are committed to some implausibly strong quasiCartesian or religious doctrine) it seems highly questionable that it can mean anything at all to talk about travelling back into the past. For there is no genuine person - no you or $I$ - who can intelligibly be regarded as undertaking such a journey.

(ix) If we imagine ourselves as pure spirits observing the past, then we would be pure observers, not genuinely able in any way whatsoever to be involved in the past. (For example: we then cannot feel anything physical, for fear of altering the past, such that it is no longer the very "place" thatwewished to "go" to. "Our" supposed "journey" into the past(and, presumably, to be of anyuse to us and to others, backagain, to the present, to our embodied selves) could not involve any change at all in our actual physical existence as we are, alive, here and nowthe "you" that travels back into the past has very little connection, it seems, with the flesh-and-blood you reading this paper.) Indeed, there is a very serious issue about whether one can make sense at all even of the concept of being a "pure observer." For what is it that then 
observers, and bow?: Can such an "observer" see anything? Hear anything? ${ }^{2}$ Surely one would not really be there, and could not truly be said to observe anything at all.

(x) But perhaps all is not lost; for, in this case (i.e. vis-a-vis the past), it seems nevertheless that there is something that it can be - that it can mean - to speak of $u$ - the actual people, flesh-and-blood creatures, that we are - travelling back into the past. Namely: seeing photographs, watching films, reading archaeological evidence, etc. As Frank Ebersole remarks: "A dramatic archaeology professor might say We are looking at the distant past' while displaying some unusually realistic paintings of pre-historic man" ${ }^{3}$, etc. Some would say the same, while looking at the stars. ${ }^{4}$ (One might of course also speak of travelling through time, into past or future, by means of dreams, stories, memories, prophecies, etc. I have no principled objection to that.)

(xi) You really can see the past: exactly as it has come down to us. One might put it this way: one already has in one's possession a timemachine, if one has a camera - or a photo-album. (And in any case: If all you want to see is something resembling the past, then certainly photos and paintings, etc. are quite good enough. As good as "going back into the past" - such that it was inevitably only something resembling what you wanted to "travel back into" that you saw, not the thing itself - would be...)

(xii) In other words: just as there is no good reason not to use the term "travelling into the future" to describe the phenomenon of going to sleep, unless we (quite reasonably - see sections 10-12, in Part I,

2. Compare for instance P.F. Strawson's useful argument in Ch. 2 of his (Strawson 1959). And Ebersole's at p. 114 of his Ebersole (1979). As I point out in section (x), below: a real person could not only observe, but can moreover under some circumstances be meaningfully said to observe the past.

3. p. 526 of Ebersole's "How philosophers see stars" in his Ebersole (1979).

4. I allude here to the view of A. J.Ayer (e.g., The Problem of Knowledge (Ayer 1956) pp. 94-5), and similar views in Chisholm (see p. 153 of his Chisholm (1957)), Russell (see Human Knowledge, its scope and limits (Russell 1948), p. 205f.) and Whitehead, to the effect that we can know/see the past, and indeed only the past. These views are beautifully presented, dissected and their attractions greatly diminished, in and by Frank Ebersole's "How philosophers see stars" (Ebersole 1979). In effect, my argument in the present paper explores a corollary of Ebersole's line of thinking. If philosophers and others are so keen to "travel through time," then they might as well just look outside the window at night. For it is in a certain (albeit a stretched, and as Ebersole so patiently argues, ultimately probably dissatisfying, misleading) sense true that we are seeing events that happened earlier, when we do so. Only: this is of course still most unlikely to satisfy the one who wanted to "travel through time." And the reason why this is so, is the very reason that Ebersole presses: because saying that we see the past when we see the stars is in the end likeliest merely to be a piece of (merely) linguistic/lexicographic revisionism, not in any sensical sense an exciting discovery. 
above) insist upon being able then to travel back into (what has then become) the past, so there is no good reason not to use the term "travelling into the past" to describe being pure observers of the past, without affecting it, as we can observe the past in numerous ways already: in old footage, in art, and so on, plus of course by means of others' recollections (and our own). But, once more, this will seem unsatisfactory (and quite reasonably so!), not what we wanted when we spoke of "travelling into the past."When we used the term "time-travel" to refer to "travelling back into the past,"we did not want to end up only (making sense by talking about) looking at old photographs, etc.

(xiii) But this is the best that we can mean.

(xiv) Therefore there is (and can be) no such thing as travelling into the past in the sense in which we imagined (that we imagined) that there could be.

(xv) Therefore (given also sections 11 and 12 in Part I, above), there is and can be no such thing as time-travel. For what was necessary in order for us to be willing to call something "time-travel" (namely, its being meaningful to speak of travel "back into the past") is just not available. Our relation to the past is necessarily spectatorial, in a doubled sense: We cannot interfere with it, and we cannot even observe it except from a temporal distance. It turns out that it means nothing to suppose otherwise. (This is why our statements about the past are truth-apt, and have an "answerability" (in roughly Travis's sense of that word) - to something independent of us. This is the reality of the past, and it directly implies the wrong-headedness of constructivism about the past.)

(xvi) By rough analogy with Russell's paradox, we might put the insoluble problem in this way: The creator/user of a time-machine has set herself a non-existent task. She has to travel back into the past of all those people who do not travel back into their own pasts. ${ }^{5}$ If she is such a person, then she is not.

5. Bradley Monton's "many-particle" argument ("Time travel without causal loops" (Monton 2007)), does not refute this point. For (as one sees, on closely inspecting pp. 59-60 of his paper), the particles he therein describes as time-travelling do not really travel back into their own pasts. They travel through space as well, into adjoining regions or edgeregions, and without their doing so Monton's argument would not work. Monton has no argument that enables a particle to travel back into the past (without generating a causal loop) except by simultaneously travelling to a region of space closed from the region that the particle originated in. (In practice, a different universe. Monton only manages to counter the presumption that he is presupposing a different universe by proposing particles that do not interact with any other particles - in effect, much the same as my pure-spirit would-be observers in sections (vi) - (ix), above.) 


\section{Part III: Diagnosis}

(a) The future is not a place that you can go-let alone come back from (There are no return tickets). A general underlying problem here, as I have explained and explored in previous work, is the suspect way in which we are continually tempted to use terms whose employment we only perspicuously understand spatially (e.g."travel,"“forward" and "back" ${ }^{6}$ ) in order to allegedly make sense of matters temporal. ${ }^{7}$ We understand what travelling is - through space. When we project this "language-game" into "the 4th dimension," then we potentially set ourselves up for all sort of headaches. For actually, time is, as we might therapeutically put it, a device for rating changes. ${ }^{8}$ (Changes that occur in space.) It was never intended to be regarded as an independent medium that one can travel in or through. As a result, it should not greatly surprise us that incoherences tend to multiply when one tries to take time-travel-tales seriously. What it would mean to travel "through time" has just not been carefully thought through. For instance, while time-travelling, one remains, typically, fixed in space. But hang on: the Earth is flying through space all

6. "Time"s arrow' points only in one direction: thus there is something deeply suspect about what we are wanting to do, in using terms such as "back" (and not being content only with terms such as 'forward') in relation to "time-travel." For, if we speak of the twin who travels to near a black hole as travelling forward through time, this at least will be harmless, so long as we do not then expect there to be such a thing as travelling backward through time that symmetrically mirrors what the twin undergoes. (See also on this note 60 of my Read (2007).)

7. Cf. Frank Ebersole's "The precarious reality of the past," which (at pp. 136-141 of his Things we know (in his Ebersole 1967)) explains further the attractions of the spatial and place-like pictures of past and future. (See also Part 3.2 of my Read (2007).) As I make clear there, it should not be assumed by my saying that there is always something potentially problematic about modelling time on space that I am going into competition with Einsteinian physics. For instance, at the most basic level: talk of "time-lines" and spatial mapping of them certainly need not cause any problems at all, so long as we take care (on which, see p.82f. of my Read 2007). And it is even harmless to talk of time as a dimension so long as (as physicists generally do) one distinguishes between time and "time-like dimensions" on the one hand and space and "space-like dimensions" on the other hand. I am only issuing some warning signs (reminding that employment of the word "dimension" for instance does not guarantee that all aspects of what one is talking about can be modelled on our pre-existing understanding of three dimensions, and that otherwise talk of "the 4th dimension" will be misleading) and putting down some kind of prose "constraint" on what physics can successfully mean, beyond its maths, its geometry. I am of course not constraining physics from anything - for nonsense is not any kind of realm at all. It is only an absence of successful sense-making (Cf. section III b, below.)

8. For further exposition, see p. 93 of my (Read 2007): A therapy for our habit of substantialising time, and turning it into a medium, is, as I put it there, to think "of time as at base involving comparative statements." (See also III h, below.) Wittgenstein's (1922) Tractatus is also a helpful antecedent here; see especially 6.3611: "We cannot compare any process with the 'passage of time' - there is no such thing - but only with another process (say, with the movement of the chronometer). / / Hence the description of the temporal sequence of events is only possible if we support ourselves on another process." 
the time. How come, when one travels back into the past or forward into the future, one still magically ends up being on the Earth? ${ }^{9}$

(b) A substantial body of work in linguistically-oriented so-called "Cognitive Science" now exists that can help us to understand section (a), above. When extended as I am in effect extending it here, this body of work can help us therapeutically diagnose and dissolve away the attractions of time-travel-talk. The founding text is Lakoff and Johnson's (1980) Metaphors we live by ${ }^{10}$ which powerfully argues the case that the way in which we develop temporal concepts is primarily through conceptual metaphors drawn from motion and (more generally) from spatial concepts (e.g. "Times are places"). Lakoff and Johnson, in that book and in subsequent work, develop the "Moving Time" metaphorical system and the logically-rivalrous "Moving Observer" metaphorical system for time. It is easy to see how these create an illusory space for time-travel-talk. For example, in the "Moving Time" spatialisation of time, "objects" move past the agent/ observer from the future to the past. The objects all move in the same direction - this is mapped to time always moving in the same direction. But then it is the easiest thing in the world to imagine suspending this rule, and ask why the objects should not start moving in the opposite direction. And then one generates the idea of timetravel "back" into the past... Vyvyan Evans's The structure of time (2003) takes forward, details and corrects Lakoff and Johnson's presentation of time. The point of departure for Evans's investigation is this, pertinent, question: "Why is time lexicalised in terms of space and motion through three-dimensional space and not in its own terms"? (p. 13) Evans's book is a detailed account of how and why we spatialise time. It can help afford one greater freedom with regard to the felt compulsion to spatialise that is so rampant in time-traveltalk. Time-travel-talk, I am suggesting, is a consequence of being gripped/captured by spatial pictures of time. Of plunging headlong into a spatialised view of time, without realising that one has allowed one's metaphors to run away with one. Evans's book details the various the several quite different - conceptual metaphors for time, and how they work. Evans develops (and facilitates reflection upon) the various conceptions of time involved in what he calls the "duration sense" of

9. What sense, moreover, does it have to speak simply of travelling through time, when one understands the Universe, as nowadays we do, to be something that is full of movement and change, something that is "unfolding" - and rapidly expanding - in time and space (in space-time)? (Notice that the same worry does not apply to "travelling through space": we do not mean by that, travelling through space without time passing (i.e., the allegedly logically possible phenomenon of instantaneous matter-transmission).)

10. (Lakoff and Johnson 1980). 
time, the "moment sense," the "instance sense," the "event sense," the "matrix sense" of time (roughly: time in endless ongoingness), the "agentive sense," and the "measurement sense" (time as measurable and time as measure), to name most (but not all) of the main senses of time that he distinguishes. I would put the upshot of his detailing of these roughly as follows: time is a family-resemblance concept.The various conceptual metaphors for time are not consistent, in Lakoff and Johnson's sense of that term: they cannot be non-contradictorily combined into one whole. So often, what philosophers do is to take a few of (or just one of) such metaphor(s), and proclaim that these/ this alone reflects the nature of Time, or of the universe. The great failure of the metaphysics of Realism and Anti-Realism with regard to time is of this nature: these metaphysics pretend to "capture" the whole nature of time when actually they each capture only a part of its grammar. ${ }^{11}$ Metaphysics and ontology of time (and similarly of other "things") are rash over-generalisations of or reifications of fragments of the "metaphorical patchwork" that time is. ${ }^{12}$ The same is true, I would suggest, of the endurantism vs. perdurantism (or threedimensionalism vs. four-dimensionalism) dispute within "Realism": ${ }^{13}$ The logic and detail of Evans's work can help one to see that these would-be metaphysics of time take one particular temporal conceptual metaphor (invariably, with a spatial basis: such as the concept of having parts, or slices), and unwisely project it to "capture" the essence of temporality itself.That is what Evans, Lakoff, Johnson, Ebersole and Wittgenstein can help us to see that metaphysics of time $i$ : the unaware projection of fragments of our time-talk, taken from powerful conceptual metaphors and projected onto the nature of reality itself. This awareness helps one achieve what Wittgenstein aimed always to help one achieve in philosophy: freedom from capture/ unaware-compulsion at the hands of deep conceptual metaphors (e.g. of time), without seeking, either, to leave them behind definitively. For that is a nonsensical goal. For, as Lakoff, Johnson and Evans teach us: conceptual metaphors are essential to our thought/cognition, ineliminable from any thinking of above a minimal complexity.

(c) So: to the possible objection that I am committed to dubious quasiHeraclitean assumptions in the present paper, I reply: Not at all. Rather, what I am pointing out is that "the observer-effect" differs

11. I argue this case in some detail at pp. 97-98 of my (Read 2007).

12. This term, "metaphorical patchwork," is Lakoff and Johnson's, from p. 134 of their (Lakoff and Johnson 1999). They add here that time is "fundamentally and inescapably metaphorical."

13. For detailed discussion, see pp. 108-109 of my (Read 2007). 
between time and space. It is part of what it is for there to be spatial entities such as rivers and buses and universities that you can step in and out of them from the outside. A river that you could not step into without it no longer being a river would not be a river at all (A body of water of this nature, in relation to which what Heraclitus said might be said to be right, would be, perhaps, a bucket of water, that the water mostly sloshed straight out of when you stuck your leg in and thereby displaced it (the water), such that it might indeed perhaps be reasonably said that you ccould not step into the same bucket of water twice...) But it is no part of the past that someone from the future was there. You can step into the same river twice, but you cannot step into the same moment twice (If you did, then it would not be the same moment). Or rather: it means nothing to "do" so (Unless: in memory, etc.). Clarity about conceptual metaphors for time makes this evident, and reveals the attraction of and the hopelessness of wishing otherwise.

(d) The more specific underlying problem that Parts I and II (above) bring out is that the very characteristics of the past and the future which make them the past and the future are the very characteristics which "time travel" as we would like to imagine it tries to flout. The past is very largely determinate, ${ }^{14}$ fixed, just by virtue of its being past: and "travelling back into it" requires that it not be fixed. The future is to a considerable extent open just by virtue of its being future: and "travelling forward into it" requires that we can lay down, now, fixed points "there," in the future, ${ }^{15}$ as of course we would do in the ordinary nature of things, in the ordinary course of events, if we were (say) cryogenically suspended and then emerged and started doing things, living again. Our desires in relation to our words come to grief, hereabouts. We want both to be able to speak of "the past," history; and for it to be present, being made. Wewant both to be able to speak of "the future," what is to come; and for it to be present, now (to us). We are hovering between incompatible uses of our words. We have to decide how to use them. We could decide to speak

14. I am leaving a little room open for the kind of phenomena described by Ian Hacking as "indeterminacies in the past," such as whether people who had what we would now call "Dissociative Identity Disorder" (DID) actually can be truly and simply said to have had DID, before the concept was invented/discovered. See Ch. 17 of his (Hacking 1995).

15. Ebersole's "Was the sea battle rigged?" (in his Things we know (Ebersole 1967) is a wonderful diagnosis of how (wittingly or unwittingly) we can find ourselves as philosophers drawn to picture the future as fixed or wish it to be fixable "in advance." We fail to differentiate the future adequately from the past. (See especially p. 220, against the desire to say that there can be fixed points in the future, things we can lay down as true, by means of (say) a time-machine.) 
of remembering things (or at least: of "flashbacks," etc.) as travelling through time into the past; but it would probably usually be much more trouble than it was worth to do so. We could decide to speak of going to sleep as travelling through time into the future; but such revisionism would surely be pointless, or counter-productive. It seems better to give up (most of) our use of the term "time-travel," except to index certain fantasies that are dependent upon illusions/delusions of sense.

(e) We desire to fluidise and experience "directly" the past, and to experience "directly" and fix the future. This is a perfectly natural human desire. (And it partly explains the enduring appeal of narratives of "time-travel," from H. G. Wells to StarTrek and Dr Who and Back to the future and the Terminator series and so on and on.) But: it is perfectly hopeless. (And so: these narratives are in the end nonsense - from start to end. ${ }^{16}$ ) It does not mean anything, to travel into the past and kill one's own grandfather, or to do anything else "there." The great failing of David Lewis's (1976) famous 1976 paper, "The paradoxes of time travel" is that (at p. 149) it abjectly fails to explain why it is impossible for a time-traveller to kill their grandfather. But on my account, a compelling reason is available to explain roughly this. Namely, that we have not succeeded in giving any stable meaning to the notion of "backward time travel." Such that no meaning has been assigned to "travelling into the past" to meet and kill one's grandfather; nor to "travelling into the future" to meet one's own grandchild, except in the normal way (i.e. by means of living, and getting a decent amount of sleep en route). If one could travel into the future and meet one's own grandchild (I mean a grandchild unconceived at the time one "left"), then one could travel back into her past and kill one's sexual partner (or for that matter, oneself) - the same "grandfather paradox" ${ }^{17}$ arises, as if one goes back into one's own past and kills one's own grandfather. One wants to lay

16. Of course, there is much in these narratives that is still of value. For example:

(1) They have of course all sorts of ethical and existential and political interest, etc.;

(2) They sometimes seem to rise to self-reflexive awareness of their own nonsensicality, in ways that are interesting and harmonise with the argument of my paper: that is one type of value that they can have. See for instance the apparent emerging awareness in the recent (2009) Dr Who story The End of Time that it cannot make sense for the "Time Lords" to exist except as pure spirit. If one then realises that that in turn cannot make sense, then the concept is at an end. Except in the kind of way that we can be amused or boggled by nonsense-poems... which brings us to;

(3) Perhaps most interestingly of all, they sometimes perhaps involve a deliberate nonsensicality, a deliberate running against our fantasised cage. A bringing into prominence of the nature of Dasein through a fantasised escape from it.

17. Due originally to Rene Barjavel's (1943). 
down fixed points in the future. One wants, hopelessly, for the future to have (already) happened, when one "returns" to what is then the past.

(f) Given this, it is perhaps worth taking a moment to reflect on why "time-travel" is such a relatively modern idea, more modern/recent than space travel. We might venture the following two speculations on this question: (i) It is unsurprising that space-travel has been thought about for a longer time; for it makes sense. (ii) In any case, "time-travel" is not a particularly attractive idea until one has a sense of a common time applying across at least one's own country. Until a couple of centuries ago, there were disparate times even within most relatively "developed countries." Until there is a certain definiteness to time, there is little sense to fantasies of travelling through it-because it is relatively clear that there is in the relevant sense no "it."

(g) In (e), I stressed an asymmetry between our desires vis-a-vis "travel into the future" on the one hand and "travel into the past" on the other (namely: the desires, respectively, to fix what is fluid, and to fluidise what is fixed).There is also a partial symmetry between them. Namely: To desire to visit the past is to want to really be there and genuinely experience it ... without affecting it. It must remain fixed. But it cannot remain fixed if you are actually to " $g_{0}$ " there. Similarly: The desire to visit the future is the fantasy that there is something definite going on there that is already visitable. Something that is fixed. But your being there and experiencing the future as something actually bappening where people undertake actions, etc. requires that it be fluid. So: one wants to lay down fixed points in the past-but the laying down of such points stops it from actually being the (your) past, what you wanted to travel into. And: one wants to lay down fixed points in the future - but the laying down of such points (whether it is you or others who lay them down) stops it from actually being the future, what has not yet happened, what is not yet fixed.

(h) "Time-travel" supposes that past events, "events in the past," are still somehow there now. The past allegedly exists now, because you can go to it now (or could, if you had a time-machine). But: those events are over.You want to be present at events that are over. ${ }^{18}$ As suggested in (a) and (b), above, talk of "the past" and "the future" can easily confuse us. It may be better, when such confusion beckons, simply to

18. Similarly, Lakoff and Johnson point out (at pp. 158-9 of Philosophy in the flesh, Lakoff and Johnson 1999) how the flow-of-time metaphysics makes the future seem like it exists now - thus it prepares the ground for the nonsense of time-travel to seem like it must make some sense. 
talk about before and after. That way, one can accomplish all that one needs to in ordinary life-and the Einsteinian physicist can say all that $\mathrm{s} /$ he needs to say, complexifying that talk-but one does not create the unwanted impression that the past and future are explorable "countries," in the way that time-travel tall tales typically do.That is the impression that one needs to overcome: that, in the sense in which we speak of tourism in space (or indeed space-tourism!), there can be time-tourism. The past is not an undiscovered or unexperienced country. 1900 is no more truly "out there (somewhere)" than is that elusive room that we see "inside" the mirror. Do not let deflationary, potentially-therapeutically-useful expressions such as "The past is fixed" mislead you into thinking that the past is still there waiting to be visited. It is precisely because there is (now) no there there that the past is fixed, unalterable.

(i) It can seem that it means something to talk about "time-travel"; a patina or ring of sense accompanies the things one wants to say, including some of the things that I have said (I mean: the things / stories that I have described, mentioned; the desires that I have tried to inhabit) in the above. But this ring of sense is only the sound (as if) of sense, not the actuality of it. As with Wittgenstein's (not unrelated!) question, "What time is it on the Sun?" The question appears well-formed. But, unless and until we find a genuine use for it that reflects to some degree at least the reason why we were inclined to ask it in the first place, the correct conclusion to draw is that it is actually not. It is (latent) nonsense.

(j) It will be objected that what I seem to be saying is that because the grammar of our language does not accommodate time-travel then it (time-travel) is not possible. It will be objected, in other words, that I am illicitly inferring from the limits of our language to an alleged limit to the possible nature of our world. But I might just as welljust as rightly - have said this: "Because the grammar of our language does not accommodate sdlfhjdsfg, then sdlfhjdsfg is not possible." Because, strange as it might sound, that is basically correct. Because sdlfhjdsfg is nonsense; it has not yet been successfully assigned any meaning; so "it" certainly is not possible. There is, we might usefully say, no "it." And the same is true of (what we seemingly wanted to mean by) time-travel. What my argument tests is "only" the claim that it means anything (of the kind that we evidently wanted to mean) to talk about time-travel. Just as it does not mean anything to talk about sdlfhjdsfg.... Of course, in the case of sdlfhjdsfg, it is harder to imagine someone wanting to say that "it" is possible. But the only difference here is a psychological one. Sdlfhjdsfg is patent nonsense, time-travel is latent nonsense. 
(k) My thinking here is also Wittgenstein's. Compare with my line of thinking in (j) his important remark that "Though it is nonsense to say 'I feel his pain', this is different from inserting into an English sentence a meaningless word, say 'abracadabra'. . . and from saying a string of nonsense words. Every word in ['I feel his pain'] is English, and we shall be inclined to say that the sentence has a meaning. The sentence with the nonsense word or the string of nonsense words can be discarded from our language, but if we discard from our language 'I feel Smith's toothache' that is quite different. The second seems nonsense, we are tempted to say, because of some truth about the nature of the things or the nature of the w orld... The task will be to show that there is in fact no difference between these two cases of nonsense, though there is a psychological distinction in that we are inclined to say the one and be puzzled by it and not the other. We constantly hover between regarding it as sense and nonsense, and hence the trouble arises." 19

(1) An objector might continue to insist that I have shown, at most, that time-travel is "only" conceptually impossible. But this is just another version of the objection considered in (i) (and (j)). If I have succeeded in convincing you that our concepts do not allow for there being anything worth calling "time-travel," then that is quite enough. Gestures at other we-know-now-whats or we-cannot-says are of no interest, no substance. Could we be completely wrong about the nature of time? No. Or: there is no sense that we can make out of a "Yes" answer to such a question. A "Yes" answer to it opens the door to unconstrainedly saying just anything at all that we might feel inclined to say, Humpty-Dumpty-style. ${ }^{20}$

(m) So: we see that actually my title is a little inaccurate. There is of course no bar on using the term "time-travel." (This point distinguishes my (therapeutic, Wittgensteinian) approach clearly from a Hackerian approach, which would proceed rather by trying to insist that certain expressions simply must be taken "out of circulation," that (as it were) our language itself insists on it. Whereas at every point I appeal to my reader: It is asyou please whether or not to continue to use these terms (such as "time-travel"). But it seems to me that the attractions of so doing have (not inconsiderably) waned.) There is no

19. Italics added. Quoted from unpublished Lectures of Wittgenstein's, on p. 106 of Diamond, C. (1991).

20. Those unconvinced by this, and looking for further reason to believe it, are requested to consult Sharrock and Read's (2002) Kuhn, which makes the (Kuhnian) argument that it means nothing to contemplate giving up on our "paradigms" completely, except with a view to replacing them with some concrete alternative, which invariably cannibalises the old paradigm. 
word-policing going on here, no banning of talk of "time-travel"; it is just that "it" is unlikely to be what we (thought we) had in mind when we wanted to employ the term in the first place. One's desire to employ the term "time-travel" is likely to shift in inverse proportion with the meaningfulness of the scenario one is describing by using the term.

(n) A more accurate (though less snappy) title for the present paper might then be:"It is as you please ${ }^{21}$ whether you call anything 'time-travel' or not, but anything you end up successfully and sensically continuing to call 'time-travel' is not going to be the very kind of thing that made you want to speak of 'time-travel' in the first place."

(o) That is: in the "sense" (which turns out to be no sense at all) in which we have an internally-consistent desire to speak of time-travel, we might just as well say simply that there cannot be any such thing. ${ }^{22}$

\author{
School of Philosophy \\ University of East Anglia \\ Norwich \\ NR4 7TJ \\ r.read@uea.ac.uk.
}

\title{
References
}

Ayer, A. J. (1956). The Problem of Knowledge. London: Macmillan.

Barjavel, R. (1943). Le voyageur imprudent ("The Imprudent Traveller"). Paris:

Denoel.

Chisholm, R. (1957). Perceiving: A Philosophical Study. Ithaca: Cornell University Press.

Diamond, C. (1991). The Realistic Spirit. Cambridge, MA: MIT.

Ebersole, F. (1967). Things We Know. Eugene: U. Oregon.

. (1979). Language and Perception. Washington, DC: University Press of America.

Evans, V. (2003). The Structure of Time: Language, Meaning, and Temporal Cognition. Amsterdam: John Benjamins.

Hacking, I. (1995). Rewriting the Soul: Multiple Personality Disorder and the Sciences of Memory. Princeton: Princeton U. Press.

Lakoff, G. and P. Johnson (1980 (2003)). MetaphorsWe Live by. Chicago: U. Chicago Press.

21. See Wittgenstein's Philosophical Investigations (Wittgenstein 1958), section 16.

22. Acknowledgements: Thanks to Weggi Weggis and to a number of students over the years for help thinking these matters through. Thanks to an audience at the University of East Anglia for very useful feedback and discussion. And many thanks to Angus Ross, Don Levi, Wes Sharrock, and a referee, for very helpful comments on an earlier draft. 
Lewis, D. (1976). "The Paradoxes of Time-Travel." American Philosopbical Quarterly 13 (4): 145-152.

Mellor, D. H. (1998). Real Time II. London: Routledge.

Monton, B. (2007). “Time Travel without Causal Loops.” Philosophical Quarterly 59 (234): 54-67.

Read, R. (2003). “Against “Time-Slices”." Pbilosophical Investigations 26 (1): 24-43.

. (2007). Applying Wittgenstein. London: Continuum, L. Cook.

Russell, B. (1948). Human Knowledge, Its Scope and Limits. London: George Allen.

Sharrock, W. and R. Read (2002). Kuhn. Oxford: Polity.

Strawson, P. F. (1959). Individuals. London: Routledge.

Wittgenstein, L. (1922). Tractatus Logico-Philosophicus. London: Routledge. _. (1958 [1953]). Pbilosophical Investigations. London: MacMillan. 